\title{
Estimating the Probability of Bankruptcy Using Z-score and Distance to Default Model: An Application on Istanbul Stock Exchange
}

\author{
IFTIKHAR ALI \\ Faculty of Social Sciences, Istanbul Aydin University, Turkey \\ Note: This article is generated from the Master' Degree Thesis. \\ Email: iftikarali89@gmail.com
}

\section{ÇĬ̄EEM ÖZARI}

Faculty of Economics and Administrative Sciences

İstanbul Aydın University, Turkey.

Email: cigdemozari@aydin.edu.tr

\begin{abstract}
Since 2008, global crisis promoted individual businesses and multi-national corporations to file for bankruptcy, creating crucial social implications. Despite the fact that with the intrusion of governments and financial institutions to encourage the economy that has put corporations in billions of dollar of debt, reduces the prime rate to almost zero, increases unemployment rate and a decrease in the income rates. A countless opportunity was available to understand the facts of this economic fallout. It had become essential to predict the bankruptcy more seriously to minimize the economic crisis for corporate sector. The objective of the study was to examine the performance of Altman's Z-score and Distance to Default model by data analysis to predict the chances of bankruptcy of Turkish stock listed companies between the years 2007 to the year 2016. This study also provides an overview on the subject of bankruptcies and their harmonic effects on the global economy. The result shows the projection that Z-score model clearly outperform in predicting the bankruptcy than Distance to Default model. Additionally, this research provides a better risk management to creditors, small businesses to improve their current operations to minimize failures and invest in healthy organizations and to short unhealthy ones.
\end{abstract}

Keywords: Altman Model, Distance to Default Model, Bankruptcy Prediction, Credit Risk, Financial Ratios.

\section{Introduction}

World's financial and economic situation after economic recession badly affected the economic growth, bankruptcy rates, and unemployment. In the United States and Europe, the rate of high-yield bond and leveraged loans crossed the threshold limits in 2009, which create extreme financial uncertainty and instability for coming years. More than 200 corporates having loans of around $\$ 120$ million filed for bankruptcy protection with other liabilities of $\$ 600$ billion under chapter 11 in the United States. More than 40 of these defaults involved firms having more than $\$ 1$ billion in liabilities, with world brand organizations like Capmark Financial group, Nortel Networks, General Motors corporation individually at least $\$ 10$ billion in terms of liabilities. Undoubtedly, 2009 was marked the peak bankruptcy year in case of chapter 11 liabilities. 
The drive of this research is to study the performance of bankruptcy prediction models; the financial ratios based Z-score and Distance to Default model to give investors an incentive to purchase a bond that is less risky or risk-free. This study will explore the research literature and find some definitions of bankruptcies and its reasons. The research will provide the overview on the subject of bankruptcies and their harmonic effects on the global economy. Then the study will represent the theoretical model, which will be used in research, and will discuss the research design, methodology etc. This research will specifically test the following hypothesis: a. Merton model and Z-score formula are significantly accurate to imply on Borsa

Istanbul Stock Exchange. b. Null hypotheses. c. Comparing Distance to Default model and Z-score model. Finally yet importantly, this research will provide the crux of the whole research, along with findings study will also provide a recommendation, limitations, and suggestion for the work. The focal point of this study is to give the answer of following questions: What is the impact of Altman Z-score and Merton model on Borsa Istanbul stock listed companies and what is the difference between these models? This study aim at to unveil the capability of the enterprises to withstand against bankruptcy using bankruptcy prediction models and to find how effective the financial strategy of the enterprises is. The research of the study is organized as follows. Section 2 provides the literature review of bankruptcy forecasting models and financial distress situation. The major focus of the review is on Altman's Z-score model and Merton's Distance to Default model. Section 3 gives an overview of research design and the research methodology, data sample, empirical and mathematical results. Section 4 briefs a summary and conclusion of the findings.

\section{Literature Review}

The word "Bankruptcy" has been derived from an Italian word 'Banca rotta' a common perception that a creditor who broke the bench of a trader when he was unable to pay his debt (Depoorter \& Cabrillo, 1999:1-3) used it. Although bankruptcy has always been got attention historically after the 1980's it has become more visible and controversial (Jackson, 1985:1-2). The research on financial distress and bankruptcy conducted by Senbet and Seward in 1995 reveals that the dispute on these areas is still unsolved and numerous chances still exist for further research. The financial crisis of 2008-9 exposes this area into public domains when many financial institutions have ruined and rescued by the government (Senbet \& Wang, 2012:2).

Traditionally, Bankruptcy law is researched by lawyers not economists but in the recent decades, many research publications have been made on economies of bankruptcy. With the least possible communal cost, economists and creditors analyze the bankruptcy as the legal instrument to achieve promising results. Legal instruments theory explains the fairness and equity aspects of bankruptcy (Depoorter \& Cabrillo, 1999:1-3). Research of bankruptcy in view of the empirical evidence means to recognize financial qualities of those organizations that are probably going to petition for bankruptcy and recognize them from those that are most certainly not. The objective of predicting such bankruptcy forecast models is to anticipate which organizations will potentially petition for bankruptcy a couple of years earlier to the genuine recording. The models that foresee bankruptcy have been developed from the financial ratios usually used in financial statements issued by the organization time to time (Pestalozzi \& Timisoara, 2014:17).The literature on bankruptcy models has its roots back to 1930's when first time financial ratio was used to predict future bankruptcies. That research was conducted on 24 financial based ratios of 29 or more firms to find out the identical attributes of deteriorating firms. These 29 firms paved the path to developing average ratios. These average ratios were compared to the ratio of each firm individually to show that failing firms displays some similar trends.

In 1932, Fitz Patrick studies 13 financial ratios of effective and unsuccessful organizations. His research results that, in major cases, effective firms shows promising ratios while unsuccessful firms have critical ratios when compared with average ratios or some ratio movements. He stated Net value to liability ratio 
and Gross profit to net worth as two significant ratios. For organizations with long-term liabilities, he also reported that current ratio and the quick ratio should be placed on less importance zone.

In 1942, Merwin presented three ratios: working capital to total assets, current ratio and net worth to the total debt. He found these ratios as a substantial sign of business failure. Moreover, he mentioned that as comparing successful firm with futile one, the failed firms shows some weaknesses 4 to 5 years prior to failure (Gissel, Giacomino, \& Akers, 2007:3-5).

In Chudson's article entitled as "The pattern of corporate financial structure" direct proves can be found that's the companies can get more long-term debts who have high properties of fixed assets. Additionally, there is no direct relationship witnessed between communal size and debt ratio (Chudson, 1945:15-16). In the article, there is no model and discussion on bankruptcy but the study has been proved quite important for preparing bankruptcy prediction models.

Jackedoff (1962), presented transformations between the ratios of lucrative firms with unsuccessful ones. He found that two ratios: current ratio to total assets and working capital to total assets are higher for profitable organizations than unsuccessful organizations. As above studies show than working capital and current ratio are an important one for predicting liquidations but working capital to total asset has proved more useful than others and all these studies provide groundwork for successor studies.

Beaver (1966), used 30 financial ratios and almost 79 companies based on failure and non-failure. The result was relatively amazing. The best factor was working capital to debt ratio, which shows 90 percent correct result. The second ratio was net income to total assets of the organization and the results were 88 percent correct. Most of the researchers focus on multivariate ratios instead of single ratios (Ko, Blocher, \& Lin, 1999:73). Up-to the mid of 1960's single factor ratio was used with almost no progress in the field. First time in 1968's Altman published the multiple ratios study to predict the bankruptcy till used in todays (Gissel, Giacomino, \& Akers, 2007:7).

In Altman's analysis, the underlying example included sixty-six companies with thirty-three organizations in each group from 1946-65. The Z-score utilizes numerous inputs from corporate financial statements, balance sheets, and income statements to measure the financial prestige of an organization. The sources of info that Altman chose were from those budgetary reports that are one announcing period prior than bankruptcies. The information sources that Altman utilized were twenty-two diverse financial proportions. Altman considered that these financial ratios were wiped out measure impacts. Those proportions were partitioned into five classes: liquidity, benefit or profit, leverage, solvency, and activity. The explanation behind partitioning the information factors in case five classes is spontaneous. These are standard financial classes (Chi, 2012:7-8).

Of the various economic ratios analyzed, five $\left(\mathrm{X}_{1}\right.$ to $\left.\mathrm{X}_{5}\right)$ that really backed to predicting bankruptcy. Every ratio is allocated with a quantity in the measure of its comparative contribution. The record - the Z-score contains the duplication of each of the proportions by the suitable coefficient and expansion of the outcomes. The model, which has turned out to be standard, indicated high prescient power in regards to which organizations could face financial distress. The following list shows the coefficient and ratios:

$Z=1.2 X_{1}+1.4 X_{2}+3.3 X_{2}+0.6 X_{4}+0.99 X_{5}$

where, $X_{1}$ is working capital to total assets. $X_{2}$ is retained earnings to total assets. $X_{a}$ is income before tax and interest to total assets. $X_{4}$ is total equity of the organization total debt and $X_{5}$ is annual sales to total assets.

If the final value of $\mathrm{Z}$ is bigger than 2.99 it means the organization is in the safe zone and there are no chances of bankruptcy. If the value of $\mathrm{Z}$ is in between 1.81 to 2.99 it means there are $50 \%$ chances of 
bankruptcy. If the value of Z-score is less than 1.81 it means the organization is going to be bankrupt soon. (Altman E. , 1968).

In the course of recent years, many tests have been directed that brought about Altman's bankruptcy prediction model being around $80-90 \%$ exact in anticipating the corporate default two years earlier to the documenting under Chapter 11 bankruptcy protection code. In spite of the way that Altman's Z-score is anything but difficult to apply and incorporates different financial ratios, it is additionally criticized for not integrating all-important discerning financial ratios (Pestalozzi \& Timisoara, 2014:17-19).

As the above Z-score model is limited to stock listed enterprises, so after the publication of original Z-score model academics and researchers created a discussion that how this model could be modified to non-stock companies. So in 1977 Altman modified the previous model for non-stock companies. The modification was implemented just in the fourth ratio where the market value of owner's equity was replaced with a book value of owner's equity. Thus the new model is as following:

$$
\mathrm{Z}=0.717 \mathrm{X}_{1}+0.847 \mathrm{X}_{2}+3.107 \mathrm{X}_{9}+0.420 \mathrm{X}_{4}+0.998 \mathrm{X}_{5}
$$

Classification of bankrupt or safe is also been changed, for this situation if the $\mathrm{Z}$ score value is above 2.9, the enterprise is in the safe zone and if below 1.23 it is going to be bankrupt in coming years. The inbetween area is a grey zone, having $50 \%$ chances of bankruptcy.

The next modification of Z-score is for non-manufacturing firms, where the ratio of annual sales to total assets value is emitted. The new model looks as follow:

$\mathrm{Z}=6.56 \mathrm{X}_{1}+3.26 \mathrm{X}_{2}+6.72 \mathrm{X}_{2}+1.05 \mathrm{X}_{4}$

In this case, if the Z-score value is more than 2.6, it indicates that organization has no chances of bankruptcy if, below 1.1, it shows a distress situation for coming years. Between 1.1 and 2.6 is a grey zone where prediction cannot be clearly interpreted (Saeed, 2014:175).

Odipo and Sitati in 2008 applied the Z-score model on Nigerian banking sector and found the reasonable result in their research. The most imperative factor of using the model is that it is quite simple and easy to use, moreover it is a very low cost in its applications (Raymond, Nzewi, \& Okoye, 2014:158).

Kpodoh (2009), verified the Z-score model for the communication sector in Ghana. His verdicts proved and verified the strength of the model to predict the business and financial distress. Charles and Goodluck (2009) applied the model using the multivariate technique to find the power of the model and to differentiate between healthy and distress enterprises. The results were quite impressive for the Nigerian market sector.

Rebort Merton proposed a model in 1974 by extending the Black \& Scholes model (1973) of option pricing to conceive the credit risk of a firm or organization by illustrating the firm's equity as a call option on its assets and the creditors can be viewed as on short position on the firm's assets. This approach of Merton's raised as "structural approach" because for exhibiting credit risk the whole model trusts upon the capital structure of the organization. The formula is as follows:

$\mathrm{C}=\mathrm{SN}\left(\mathrm{d}_{1}\right)-\mathrm{N}\left(\mathrm{d}_{2}\right) \mathrm{Ke}^{-\mathrm{rt}}$

Where, 


$$
d_{1}=\frac{\left[\ln \left(\frac{S}{k}\right)+\left(r+\frac{\sigma^{2}}{2}\right) t\right]}{s \sqrt{t}}
$$

$\mathrm{d}_{2}=\mathrm{d}_{1}-\sigma \sqrt{\mathrm{t}}$

$\mathrm{C}$ is called premium of call option, $\mathrm{S}$ denotes current stock price (price of underlying asset at time 0 ), $\mathrm{t}$ represents time until option exercise (maturity of the call option), $\mathrm{K}$ is the option exercise price, $\mathrm{r}$ denotes risk free interest rate, $\mathrm{N}$ denotes cumulative standard normal distribution, $\mathrm{e}$ is an exponential term, $\mathrm{ln}$ is natural logarithm and $\sigma$ represent standard deviation of the market.

Black and Cox (1976)), Longstaff and Schwartz (1995), Leland and Toft (1996) and Collin-Dufresne and Goldstein (2001) extended and modify the model. Ferry (2013) quoted in his paper that this model has become so popular in a current business environment that it is driving prices in the credit market. The main reason for its popularity is that this model uses significant credit market factors as current Asset value and volatility of the firm, debt and debt maturity etc. In the late 1980's, Moody's KMV was the pioneer one who commercializes the bankruptcy prediction model to whom ground work provided by Black \& Scholes and Merton model. The Distance to Default model is a mathematical deduction, which is built upon the assumptions that an organization can default over its financial commitments if its assets have less worth than its liabilities (Miller, 2009:2). The structural model could not get critical fame due to the fact of failing to reconstruct the level of credit spreads that is observed in common practices. However, their performance can be increased as suggested by Hull, Nelken \& White (2003), by calculating the spreads which use the dimensions of a traditional approach like outstanding debts, volatility, and instantaneous equity. Gemmill (2002) proved that model performed well in the case of a zero-coupon bond that is used for funding.

Campbell \& Taskler (2003) determine that equity volatility helps to explain variation in bond prices. They fit a linear model and explain the important instructive strength of historical volatility if a lot of explanatory variables. Altman, Brady, Resti \& Sironi (2003), examine the association between the probability of default and rate of recovery on the assets and empirically explain this significant relationship. They found recovery rate as a key variable in their research. All the above mentioned finding support the fact the equity market is a key point in default model which cannot be emitted or ignored if the strong alternative is not available. All this research strengthen the structural framework of Merton model of default. The structural model basically uses to find the relative probability of default and credit risk swaps and very fewer researches can be found which supports the approach to find joint probabilities of default for many enterprises. But the issue is quite critical for credit analysis, valuation of credit derivatives and for risk management. Now the credit derivatives are considered the most growing financial tool in the derivative markets (Cathcart \& ElJahel, 2004:1-3).

Lara \& Lina (2004) explain the integrated context for the calculation of single and joint probabilities, Moreover, the results are in closed form and can be used to compare with the more complex sweeping statement. They extend that credit quality changes with time and default probabilities have a direct impact on credit analysis and risk management.

The study conducted by Hillegeist (2004) inspects the occurrence of commercial bankruptcy in the United States, also discover that the PPD conducted by Black \& Scholes is more significant that others like Altman (1968) and Ohlson (1980). Not like the previous study of bankruptcies, which concentrates on determining exactness test to look at model execution, the research utilizes comparative data content tests to differentiate about the out of sample presentation of every bankruptcy models. By considering a specimen of almost 79,000 corporate year perceptions and almost 750 initial liquidations during the period of 19802000 , log probability proportion tests demonstrate that the probability of default assessed from the organizational model comprises essentially more data in measuring bankruptcies than any of the bookkeeping based bankruptcy prediction models (Tanthanongsakkun, Pitt, \& Treepongkaruna, 2007:5-6) 


\section{Study Models}

Bankruptcies increased in Turkey to 1112 enterprises in June from 861 companies in May 2017. Bankruptcies in Turkey be an average of 684.24 Enterprises from 1995 up to 2017, reaching an all-time high of 3113 Enterprises in January of 2013 and a record low of 11 Companies in October of 1995. The sample includes Turkey based financial, manufacturing, non-manufacturing firms listed in main stream market of ISE. The primary data source is the Borsa Istanbul Stock exchange with a total number of 561 firms. After studying this research is limited to ten firms. The data sample collected for the study is consists of a total 10 public listed organizations, spanning the years 2007 to 2016.

\section{Accounting Based Model}

Z-score is the formative accounting based model. It was first introduced by Altman (1968) and is used widely as a benchmark in the literature of bankruptcy prediction. By using MDA (multiple discriminant analysis), he chooses the linear combinations from different financial ratios that differentiate between bankrupt and non-bankrupt firms 2 years prior to the bankruptcy.

$\mathrm{Z}=1.2 \mathrm{X}_{1}+1.4 \mathrm{X}_{2}+3.3 \mathrm{X}_{2}+0.6 \mathrm{X}_{4}+0.99 \mathrm{X}_{5}$

where; $\mathrm{X}_{1}$ is working capital to total assets, $\mathrm{X}_{2}$ is retained earnings to total assets, $\mathrm{X}_{\mathrm{a}}$ is income before tax and interest to total assets, $X_{4}$ is total equity of the organization total debt and $X_{5}$ is annual sales to total assets.

\section{Market Based Model}

Distance to Default prediction model is a market-based model. Conservative market-based model follows the derivative pricing model of Merton and the option pricing of Black and Scholes and derive the Distance to Default model, which is applied to accumulative density function. There are two assumptions used in option pricing model: First one is the total firm value which typically follows a Brownian motion and total debt or loss is a discounted bond with maturity T. Option pricing model define the equity of the firm.

$\mathrm{E}=\operatorname{AN}\left(\mathrm{d}_{1}\right)-\mathrm{e}^{\mathrm{rt}} \mathrm{MTL} \mathrm{N}\left(\mathrm{d}_{2}\right)$

where; $\mathrm{E}$ is the value of firm's equity, $\mathrm{A}$ is asset value, $\mathrm{N}$ is the standard normal distribution, $\mathrm{e}$ is the exponential function; MTL is the market value of total liabilities, $r$ is the interest rate and $t$ is maturity time. Equity is basically the amount invested by an enterprise in a business or market, and any accumulated profit. Here equity means the annual market value of equity.

Since this study chooses the data after 2007, it does not contain any calculation. Data is directly imported from the financial statement taken from public disclosure platform. Volatility (denoted by V) means the fluctuations in the market due to some event. It is calculated from historical equity return data. As the stock price follows the Brownian motion under some assumptions, thus the help of following formula calculates volatility.

$$
\begin{aligned}
\sigma_{E} & =\frac{\frac{1}{t-1} \Sigma\left(\mathrm{u}_{\mathrm{i}}-w\right)^{2}}{\sqrt{\frac{1}{n}}} \\
u_{\mathrm{i}} & =\ln \frac{s_{\mathrm{i}}}{s_{\mathrm{i}}-1}
\end{aligned}
$$


where $\mathrm{t}$ is the time period, $\mathrm{s}$ is the stock price and $\mathrm{u}$ the log return for time $\mathrm{t}$.

The total debt $\mathrm{D}$ is the sum of short term and long-term liabilities and can be calculated from the annual report of the firm.

In the case of Merton model default point is the sum of short term liabilities and $\mathrm{k}$ times long term liabilities. Here $\mathrm{k}$ is the strike price, which is generally taken as 0.5 . However, this default point is based on Turkish companies. The maturity $\mathrm{t}$ is taken 1 year in the calculations. The return rate $\mathrm{r}$ determines that how much effectively an organization uses the capital investment from shareholders to generate profit. High return rate means more revenue. An organization can compare their return rate with the common stock rate of the same business of its competitors to check the financial health of their firm. Here risk free return rate data will be directly extracted from ISE.

\section{Research Methodology}

First of all, volatility of the market is calculated from the past data during the period on which this study is conducted. The outcome of the study will be observed according to the original model developed by Altman in 1968 and according to the DD model. Analysis of the study will be done by calculating the both models. Analysis of Hypotheses will be done by ranking $\mathrm{Z}$ for both acute values: The first category $\mathrm{Z}$ scores greater than 2.99, second category - Z-scores below 1.80. Altman (1968) initiate that this value differentiates best between bankrupt and non-bankrupt firms. Firms in the first group will be classified as stable, while firms in the second category will be classified as being at risk for bankruptcy. Then, the percentage of companies correctly classified and the percentage of companies incorrectly classified will be calculated. The percentage of correctly classified companies will reflect the predictive accuracy of the Altman Model. Similarly, percentage of PPD will describe the accuracy of DD model. PPD near to $100 \%$ means firm is near to bankrupt while on the other hand if PPD is near to $0 \%$ means firm is in the stable zone.

The method adopted here to calculate market volatility is simple moving average volatility also known as historical volatility. For that purpose, historical series of closing prices is needed which is recorded from the market on daily basis. Here in the table below is the data are taken from the google for 15 days. Typically, calculation of these values is done on yearly basis. Here the $1^{\text {st }}$ column is showing the dates in which market was open. The $2^{\text {nd }}$ column is showing the closing prices. The $3^{\text {rd }}$ column is showing the daily return or daily $\log$ return. The daily $\log$ return is the natural $\log$ of today closing price divided by the previous day closing price. For instance, if the today closing price of the market is $\$ 23$ and the previous date closing price was $\$ 22.9$. The daily log return will be LN (23/22.9). After that variance is calculated from this series of daily log return. The formula for the variance is mentioned below in the equation.

$\sigma_{n}^{2}=\frac{1}{m-1} \sum_{i=1}^{m}\left(u_{n-i}-u\right)^{2}$

Here, $\sigma$ is representing the sample variance. $M$ is number of days which is 15 days for the current example. $u_{i-1}$ is showing the mean of daily log return.

Practically the below mentioned formula can also be used for calculation. In this equation $\mathrm{m}$ is used instead of $\mathrm{m}-1$ to calculate the population variance. $U$ is representing the daily log return value.

$\sigma_{n}^{2}=\frac{1}{m} \sum_{i=1}^{m} u_{n-i}^{2}$ 
After calculating the daily variance. The square of this variance is calculated which is known as the daily volatility of the market. In the last annual volatility can be calculated.

Table 1: Closing Price of Stock Market for Company A

\begin{tabular}{|ccc|}
\hline \hline Date & Closing Prices & Daily Log Return \\
\hline $2 / 1 / 2018$ & 1167.7 & 0.048966 \\
$2 / 2 / 2018$ & 1111.9 & 0.051771 \\
$2 / 5 / 2018$ & 1055.8 & -0.02322 \\
$2 / 6 / 2018$ & 1080.6 & 0.03008 \\
$2 / 7 / 2018$ & 1048.58 & 0.045918 \\
$2 / 8 / 2018$ & 1001.52 & -0.03556 \\
\hline
\end{tabular}

The standard deviation or market volatility can be calculated from the table by the formula mentioned above, and annualizing that value to calculate the annual volatility.

The selected data is discussing the result of both models, Z-score, and probability of default shown in Table A the data of 10 years from 2007 to 2016 is selected and ratios are mentioned. $X_{1}$ is the ratio of working capital to total assets. $X_{2}$ has retained earnings to total assets, $X_{3}$ is income before tax and interest on total assets, $\mathrm{X}_{4}$ is total equity to total debt and $\mathrm{X}_{5}$ is annual sales to total assets. These ratios have been calculated by the data obtained from the balance sheets and income statement. The last column in the table represents the value of Z-score which gives an overview of the prediction of organization's bankruptcy. As discussed in the previous chapter if the value of Z-score is above the 2.99 then the organization is in the safe zone and there are no chances of bankruptcy.

If the values lie between 1.8 and 2.99 then organization lies in the gray area there maybe the chances of bankruptcy. While if the organization has a Z-value below 1.8 then it will be bankrupt in the coming years. It can be seen in the last column that most of the values lies in grey and safe zone which means that there are no chances or very little chance of bankruptcy.

Table A: Z-score Values of Organization $\mathrm{C}_{3}$

\begin{tabular}{|ccccccc|}
\hline \hline Year & $\mathbf{X}_{\mathbf{1}}$ & $\mathbf{X}_{\mathbf{2}}$ & $\mathbf{X}_{\mathbf{3}}$ & $\mathbf{X}_{\mathbf{4}}$ & $\mathbf{X}_{\mathbf{5}}$ & Z-score \\
\hline 2016 & 0.0645 & 0.2157 & 0.0682 & 1.7438 & 1.1437 & 2.7831 \\
2015 & 0.0426 & 0.2113 & 0.0765 & 1.9795 & 1.1442 & 2.9198 \\
2014 & 0.0665 & 0.2214 & 0.0650 & 1.8901 & 0.9248 & 2.6540 \\
2013 & 0.1159 & 0.2197 & 0.0698 & 3.3577 & 0.8785 & 3.5612 \\
2012 & 0.1413 & 0.2233 & 0.1002 & 2.4141 & 1.1788 & 3.4284 \\
2011 & 0.1747 & 0.2146 & 0.1332 & 2.3523 & 1.0408 & 3.3914 \\
2010 & 0.1728 & 0.2369 & 0.1341 & 2.6038 & 1.0835 & 3.6166 \\
2009 & 0.2036 & 0.2553 & 0.1486 & 2.7198 & 1.0037 & 3.7175 \\
2008 & 0.1272 & 0.3003 & 0.0200 & 2.1688 & 0.2883 & 2.2258 \\
2007 & 0.1069 & 0.2122 & 0.0377 & 2.3851 & 0.2638 & 2.2422 \\
\hline
\end{tabular}

In Figure A the graph gives a glimpse of the scenario happened during 10 years. The $\mathrm{x}$-axis of the graph is representing the number of years starting from 2007 and end on 2016. While the y-axis is showing the Zscore values. The graph clearly figures out that in the first 2 years $2006-7$ the organization falls in the gray zone but from the years 2008 to onwards the organization is continuously in the save zone while in the last 3 years organization again falls in the mixed zone but not in the distress zone. The average line is also showed in the figure which shows that organization is lying in the safe region. So generally we can say that there are no chances of bankruptcy for the organization. 


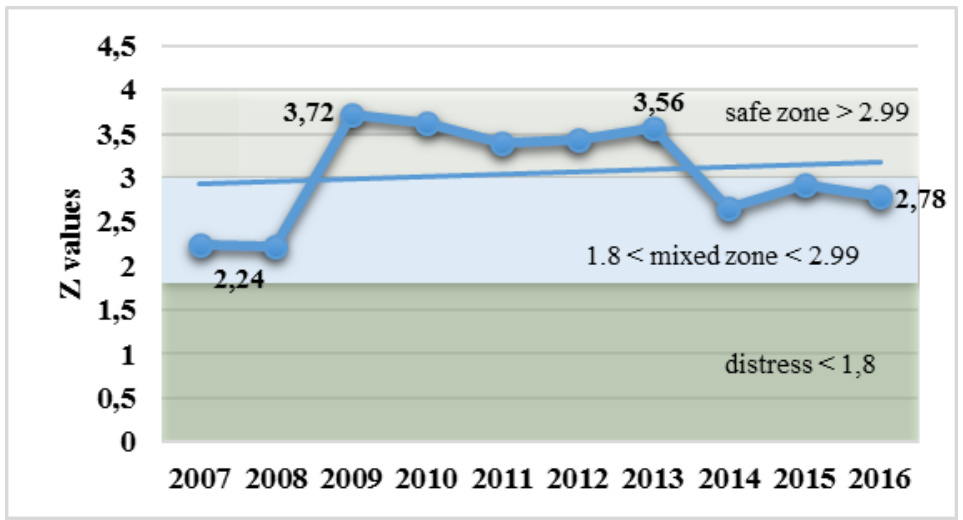

Figure A: Z-score Values of Organization $\mathrm{C}_{3}$

Table B shows the data for the probability of default model for company $\mathrm{C}_{3}$. This table is showing the natural $\log$ return of firm assets to firm equity. The $2^{\text {nd }}$ column is showing the standard deviation or volatility of the market while next column representing the default point of organization and the last column is showing the probability or chances of the organization to fail or bankrupt.

Table B: Probability of Default of Organization $\mathrm{C}_{3}$

\begin{tabular}{|lcccc|}
\hline \hline Year & $\mathbf{V}$ & (u-sigma2/2)t & $\mathbf{d}_{1}$ & PPD \\
\hline 2016 & $22.38 \%$ & 0.668 & 8.075 & 0.000 \\
2015 & $26.79 \%$ & 0.740 & 7.210 & 0.000 \\
2014 & $27.35 \%$ & 0.760 & 7.070 & 0.000 \\
2013 & $27.78 \%$ & 0.699 & 7.346 & 0.000 \\
2012 & $22.75 \%$ & 0.922 & 10.017 & 0.000 \\
2011 & $27.93 \%$ & 1.226 & 9.248 & 0.000 \\
2010 & $30.34 \%$ & 1.174 & 8.671 & 0.000 \\
2009 & $40.00 \%$ & 1.287 & 6.986 & 0.000 \\
2008 & $54.34 \%$ & 0.294 & 3.090 & 0.001 \\
2007 & $39.03 \%$ & 0.369 & 4.737 & 0.000 \\
\hline
\end{tabular}

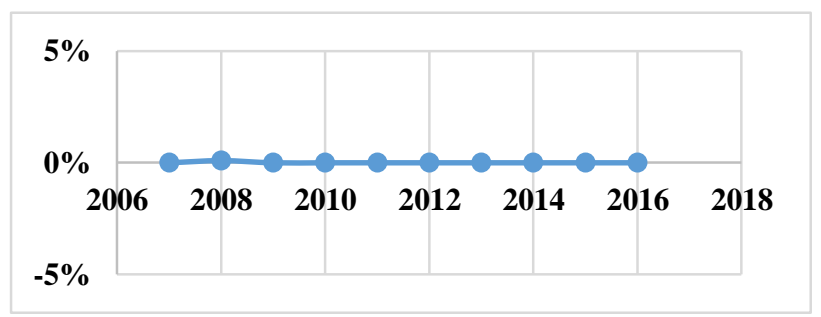

Figure B: Probability of Default of $\mathrm{C}_{3}$

Figure B is the graphical representation of Table B. The $\mathrm{x}$-axis is representing the number of years and the $y$-axis is for the PPD. As seen in the graph that the organization has zero chances of default from starting year to the end. It shows that probability of default model is confirming the results mentioned in the Zscore. It is showing that both the models are elaborating the same results and supporting each other.

Table $\mathrm{C}$ is an illustration of organization $\mathrm{C}_{4}$. The results of ratios are quite different from the previous table. As we see in the first column the working capital to total asset ratio $X_{1}$ has negative values or very small values that means the current assets are less than current liabilities causing negative working capital which 
is the cause of lower $\mathrm{z}$-score value. Similarly for the column 3 in which $\mathrm{X}_{3}$ ratio is mentioned which means that organization $\mathrm{C}_{4}$ has very low or negative income as compared to its total assets.

Table C: Z-score Values of Organization $\mathrm{C}_{4}$

\begin{tabular}{|ccccccc|}
\hline \hline Year & $\mathbf{X}_{\mathbf{1}}$ & $\mathbf{X}_{\mathbf{2}}$ & $\mathbf{X}_{\mathbf{3}}$ & $\mathbf{X}_{\mathbf{4}}$ & $\mathbf{X}_{\mathbf{5}}$ & Z-score \\
\hline 2016 & -0.124 & 0.073 & -0.036 & 0.040 & 1.745 & 1.586 \\
2015 & -0.120 & 0.088 & -0.060 & 0.098 & 1.630 & 1.455 \\
2014 & -0.176 & 0.090 & 0.033 & 0.122 & 1.452 & 1.534 \\
2013 & -0.066 & 0.087 & -0.066 & 0.099 & 1.229 & 1.101 \\
2012 & 0.006 & -0.019 & 0.023 & 0.289 & 1.153 & 1.371 \\
2011 & 0.038 & 0.013 & -0.058 & 0.279 & 1.050 & 1.080 \\
2010 & 0.005 & 0.005 & 0.014 & 0.319 & 1.143 & 1.383 \\
2009 & 0.088 & 0.024 & 0.024 & 0.362 & 1.011 & 1.437 \\
2008 & 0.158 & 0.222 & 0.111 & 1.277 & 1.752 & 3.368 \\
2007 & 0.171 & 0.226 & 0.226 & 1.080 & 1.694 & 3.592 \\
\hline
\end{tabular}

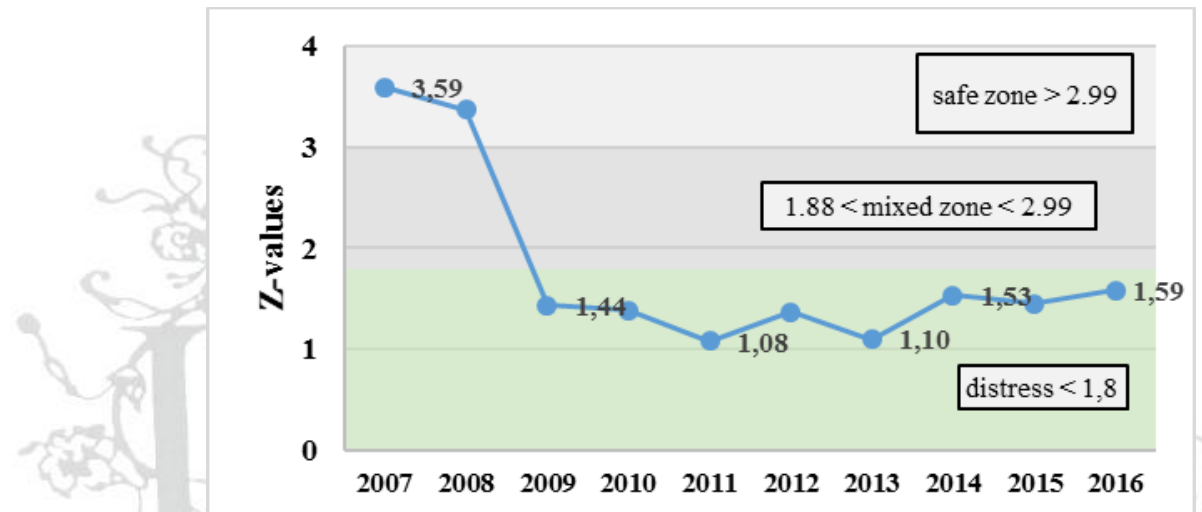

Figure C: Z-Score Values of Organization $\mathrm{C}_{4}$

Figure $\mathrm{C}$ is the graphical representation of Table $\mathrm{C}$ for the organization $\mathrm{C}_{4}$. Here a clear glimpse of the table can be seen that in the first 2 years organization was in good state and there were no chances of bankruptcy at all but as 2008 years begin the downfall of the organization had been started and till the end of period 2016 organization was in the continuous state of distress. There was a global economic crisis in the year 2008 which maybe one of the reasons for the distress situation of the organization $\mathrm{C}_{4}$.

Table D: Probability of Default of Organization $\mathrm{C}_{4}$

\begin{tabular}{|ccccc|}
\hline \hline Year & $\mathbf{V}$ & (u-sigma2/2)t & $\mathbf{d}_{\mathbf{1}}$ & PPD \\
\hline 2016 & $20.17 \%$ & -4.78 & -22.25 & $0 \%$ \\
2015 & $29.61 \%$ & -7.02 & -22.46 & $0 \%$ \\
2014 & $29.61 \%$ & 1.35 & 5.95 & $0 \%$ \\
2013 & $32.09 \%$ & 5.56 & 18.77 & $30 \%$ \\
2012 & $14.12 \%$ & 2.03 & 18.56 & $80 \%$ \\
2011 & $30.04 \%$ & -8.57 & -26.45 & $100 \%$ \\
2010 & $43.90 \%$ & 1.11 & 3.96 & $100 \%$ \\
2009 & $39.67 \%$ & 2.72 & 8.63 & $100 \%$ \\
2008 & $7.04 \%$ & 20.57 & 304.32 & $100 \%$ \\
2007 & $25.55 \%$ & 40.68 & 162.35 & $95 \%$ \\
\hline
\end{tabular}


Table $\mathrm{D}$ shows the data for the probability of default for the organization $\mathrm{C}_{4}$. The first column has quite a different result from the previous example where natural log return of assets to firm equity has large values but here have small values as compared. Similarly, the standard deviation has negative values which have deep impact on the probability of default.

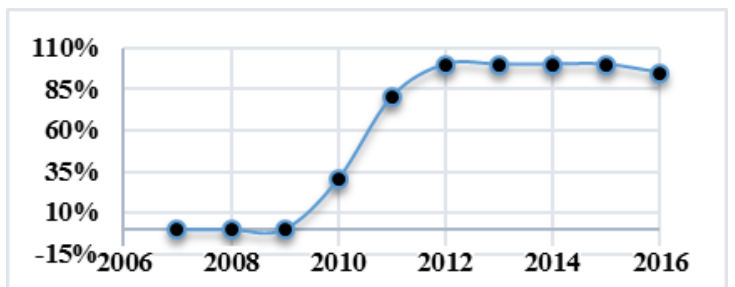

Figure D: Probability of Default of Organization $\mathrm{C}_{4}$

Figure D shows that in the years 2006-8 organization has no chances or 0 chances of bankruptcy but from the year 2010 organization had $35 \%$ chances of default which increase further in the year 2011 up to $85 \%$ and after that $100 \%$ from the year 2012 to onward. If we compare both models it strength up our theory that both the model are quite supportive of each other.

For the last part of the study; as the sample size is less than 30, two-tailed t-test is conducted. $\alpha$ value is taken as $0.05 . \mathrm{n}_{1}$ is the sample size of Z-score model which is $10, \mathrm{n}_{2}$ is the sample size of DD model which is $10, \mathrm{H}_{0}: \mu_{\mathrm{z}=} \mu_{\mathrm{p}}$ is showing the null hypothesis which means that there is no significant difference between Z-score and DD model while $\mathrm{H}_{1}: \mu_{\mathrm{z} \neq} \mu_{\mathrm{p}}$ means there is a significant difference between Z-score and DD model. The degrees of freedom is calculated by the help of the following formula and found as 18 .

df $=\left(n_{1}-1\right)+\left(n_{2}-1\right)=18$

Decision rule for the null hypothesis is that if $\mathrm{t}$ value is less than -2.101 or greater than 2.101 , we reject the null hypothesis. We calculate $t$ value by the help of following formula and found as 2.69 .

$\mathrm{t}=\frac{\left(\overline{\mathrm{x}}_{\mathrm{z}}-\overline{\mathrm{x}}_{\mathrm{p}}\right)}{\left(\sqrt{\left(\frac{\mathrm{S}_{\mathrm{p}}^{2}}{\mathrm{n}_{1}}+\frac{\mathrm{S}_{\mathrm{p}}^{2}}{\mathrm{n}_{2}}\right)}\right.}$

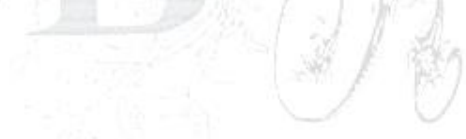

Since t value which is 2.69 is greater than 2.101 so reject null hypothesis.

\section{Results and Conclusion}

In this study, 10 organizations in the Turkish stock exchange listed were chosen, in the span of 10 years from 2007 to 2016. Earlier studies available in Turkey were conducted on a single company or in a different economic environment, and therefore it was significant to re-examine the subject on a sample of corporations and the period after economic recession of 2008. This study shows that the predictive capability of the original Altman Model for publicly traded companies is high with respect to bankrupt corporations. However, the model is less efficient in predicting stable companies and gives misleading information.

Use of the Merton Model develops the predictive ability for stable companies and, as a result, the overall predictive ability of the model. For each organization, unique set of data is collected from the balance sheet, income statements, and annual reports to meet the requirements of under study models. Data collection process was tracked by the extensive analysis of bankruptcy literature. The result showed that financial and economic data was quite dependent and individually quite a good predictor of bankruptcy. Therefore, it is hypothesized financial variables (ratios) increase the predictive power. 
It should be noted that the Altman Z-score Model for manufacturing and non-manufacturing firms is one of the appropriate tool in assessing the risk of bankruptcy for corporates and consequently other evidence, both qualitative and quantitative, must be used to appraise the solvency of corporations. This is usually done in the finance industry as part of management and governing credit risks.

The results of the study are promising because Z-score and Distance to Default model can be used to predict economic failure of companies in Turkey, even years prior to bankruptcy. This subject has been critically important over the past years, following the liquidity distress many Turkish and global companies have confronted.

The most significant gain of the models equated to more advanced ones is its simplicity and the low cost of its application. Using a neutral, quantitative indicator represented by a single number, the credit risk can be estimated. We believe the issue to be of great importance now, in light of the significant growth in recent years in the amount of information companies include in financial statements. The model allows users to focus attention on a single number in an era when we are "flooded" with financial information, when we "cannot see the forest for the trees."

Additionally, the contributions of this study have concrete applications, with respect to economic and social advantages. For stakeholders and investors, bankruptcy prediction develops risk assessment while for venders, it would be able to get additional time to shelter more sponsoring or recover current actions and operations to escape catastrophe altogether. For financiers, these models can also be used to recognize dynamic and bankrupt companies, serving individuals and corporates to invest in healthy businesses or to short unhealthy corporations.

This study examined two separate accounting bankruptcy predicting models that are quite similar in literature as compared with the current topic. As both of these portrays different financial variable and explain prediction accuracy at different stages but none of them explain financial distress completely.

As studying the literature study can conclude that these models does not provide a satisfactory statistic for failure prediction since both have strengths and weaknesses. Data is selected from historical information and trends. These trends are not included in the prediction model, which makes these models limited itself. For future research and perfections for bankruptcy prediction, several areas can arise from this work. For example: scrutinizing corporates by additional disintegration by business and geographical sectors. Applying the research methodology to other sectors like social organizations or star-ups where there is always a high chance of bankruptcy. The span of the research can be increased to get more deep knowledge about the sector. By this amount of useful data can be increased. Data can also be check quarterly to know about hidden circumstances

\section{References}

Altman, E. (1968). Financial ratios, discriminant analysis and the prediction of corporate bankruptcy. J.Finance., 589-609.

Altman, E. I., Brady, B., Resti, A., \& Sironi, A. (2003). The Link between Default and Recovery Rates: Theory, Empirical Evidence, and Implications. The Journal of Finance: Vol VLII.

Campbell, J. C., \& Taskler, G. B. (2003). Equity Volatility and Corportae Bond Yields. The Journal of finance, Vol: LVIII, No, 6.

Cathcart, L., \& El-Jahel, L. (2004). Multiple Defaults and Merton's Model. Imperial College, London. ISSN 1744-6783, 1-28.

Chi, Y. (2012). A Comparative Study of Altman's Z-score and A Factor Analysis Approaches to Bankruptcy Predictions. Saint Mary's University.

Chudson, W. A. (1945). The Pattern of Corporate Financial Structure: A Cross-Section View of Manufacturing, Mining, Trade, and Construction, 1937. NBER, 1-16. 
Depoorter, B. W., \& Cabrillo, F. (1999). BANKRUPTCY PROCEEDINGS: 7800. The University of Ghent, Faculty of Law, 1-4.

DeSmith, S., Dodyk, L., Smith, C., \& Stieg, J. (2014). Bankruptcies and Liquidations. PwC.

Gissel, J. L., Giacomino, D., \& Akers, M. (2007). A Review of Bankruptcy Prediction Studies: 1930present. Journal of Financial Education: Vol 33, 1-42.

Jackson, T. H. (1985). The Logic and Limits of Bankruptcy Law. Washington, D.C.: BeardBooks.

Ko, L.-J., Blocher, E. J., \& Lin, P. P. (1999). Prediction of Corporate Financial Distress: An Application of the Composite Rule Induction System. The International Journal of Digital Accounting Research, 6985 .

Lifschutz, S., \& Jacobi, A. (2010). Predicting Bankruptcy: Evidence from Israel. International Journal of Business and Management.

Miller, W. (2009). Comparing Models of Corporate Bankruptcy Prediction: DD vs. Z-Score. Morningstar, Inc., 1-21.

Pestalozzi, J. H., \& Timisoara, N. R. (2014). Altman's Z-Score in the Airline Business. Case Study of Major U.S. Carriers. Are they Potential Bankruptcy Candidates? International Journal of Advances in Management and Economics: Vol.3. Issue 1, 16-24.

Raymond, Nzewi, \& Okoye. (2014). Corporate Bankruptcy: An Application of Altman Model in Predicting Potential of Failure in Nigerian Banking Sector. International Journal of Empirical Finance: Vol. 2, No. $4,152-171$.

Saeed, A. S. (2014). Testing the Predictive Power of Altman's RevISEd Z' Model: The Case of 10 Multinational Companies. Research Journal of Finance and Accounting: ISSN 2222-1697 (Paper) ISSN 2222-2847, 174-184.

Senbet, L. W., \& Wang, T. Y. (2012). Corporate Financial Distress and Bankruptcy: A Survey. Hanover, USA, Netherlands: Now Publishers Inc.

Suzanne K, H., Kay A, H., \& Larry W, H. (2010). A Study of the Efficacy of Altman's Z To Predicts Bankruptcy of Specialty Retail Firms Doing Business in Contemporary Times. Economics \& Business Journal: Inquiries \& Perspectives.

Tanthanongsakkun, S., Pitt, D., \& Treepongkaruna, S. (2007). A Comparison of Corporate Bankruptcy Models in Australia: the Merton vs Accounting-based Models. The Official Journal of the Asia-Pacific Risk and Insurance Association: Vol 3. Issue 2, 1-33. 